\title{
Retrospective cohort study of the effects of obesity in early pregnancy on maternal weight gain and obstetric outcomes in an obstetric population in Africa
}

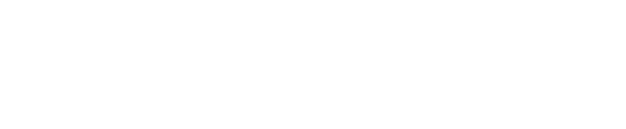

\author{
Chukwuemeka A lyoke' \\ George O Ugwu' \\ Frank O Ezugwu ${ }^{2}$ \\ Osaheni L Lawani ${ }^{3}$ \\ Azubuike K Onyebuchi ${ }^{3}$ \\ 'Departments of Obstetrics \\ and Gynaecology, University of \\ Nigeria Teaching Hospital, Enugu, \\ ${ }^{2}$ Departments of Obstetrics \\ and Gynaecology, Enugu State \\ University Teaching Hospital, Enugu, \\ ${ }^{3}$ Departments of Obstetrics and \\ Gynaecology, Federal Medical Centre, \\ Abakaliki, Ebonyi State, Nigeria
}

Objective: The purpose of this study was to compare maternal weight gain in pregnancy and obstetric outcomes between women with obesity in early pregnancy and those with a normal body mass index (BMI) in early pregnancy.

Methods: This was a retrospective cohort study of women with obesity in early pregnancy and those with a normal BMI who were seen at three teaching hospitals in South-East Nigeria. Statistical analysis was performed using Statistical Package for the Social Sciences version 17.0 software, with descriptive and inferential statistics at the $95 \%$ level of confidence.

Results: The study sample consisted of 648 women (324 obese and 324 healthy-weight). The mean age of the obese women was $26.7 \pm 5.1$ years and that of the healthy-weight women was $26.6 \pm 4.9$ years. Although both excessive weight gain (odds ratio [OR] 0.35, 95\% confidence interval [CI] 0.23-0.54) and inadequate weight gain (OR 0.08, 95\% CI 0.04-0.15) were less common in women with early pregnancy obesity than in healthy-weight women, a significantly higher proportion of obese women with excessive weight gain had adverse fetomaternal outcomes. Also, a significantly higher proportion of obese women had specific complications, such as premature rupture of membranes (OR 2.36, 95\% CI 1.12-5.04), gestational hypertension/pre-eclampsia (OR 2.31, 95\% CI 1.12-5.04), antepartum hemorrhage (OR 2.78, 95\% CI 1.02-7.93), gestational diabetes (OR 4.24, 95\% CI 1.62-11.74), cesarean delivery (OR 2.3, 95\% CI 1.2-5.44), macrosomia (OR 4.08, 95\% CI 1.06-8.41), severe birth asphyxia (OR 2.8, 95\% CI 1.2-6.63), abnormal Apgar scores (OR 2.67, 95\% CI 1.46-4.93), and newborn special care admissions (OR 1.18, 95\% CI 1.0-3.29).

Conclusion: Early pregnancy obesity was associated with a wide range of adverse fetomaternal outcomes, and could be a genuine risk factor for increased pregnancy-related morbidity and/or mortality in this population. Interventions to reduce prepregnancy obesity could therefore be useful in this low-resource African setting.

Keywords: obesity, early pregnancy, maternal weight gain, obstetric outcomes

\section{Introduction}

The increasing prevalence of obesity worldwide has prompted the World Health Organization to designate obesity as one of the most important global public health threats. ${ }^{1}$ Obesity is defined as a body mass index (BMI) $\geq 30 \mathrm{~kg} / \mathrm{m}^{2}$. Obesity is generally considered to be a disease of affluent nations, and obesity in pregnancy has long been associated with significant adverse fetomaternal outcomes in studies done mostly in Western countries. ${ }^{3-5}$ In African societies known more for poverty and disease, it is hardly surprising that obesity in pregnancy has not received much attention
Correspondence: Chukwuemeka lyoke Department of Obstetrics and Gynaecology, University of Nigeria Teaching Hospital, Ituku-Ozalla, PO Box 4998, Enugu

Headquarters, Enugu, Nigeria

Tel +2348085831 167

Email caiyoke@yahoo.co.uk 
from researchers. However, recent hospital-based studies show that the prevalence of obesity in pregnancy could be significant in urban communities in Africa. ${ }^{6,7}$

Maternal weight gain during pregnancy depends to some extent on prepregnancy weight ${ }^{8}$ and abnormal weight gain in pregnancy has been associated with adverse outcomes. A recent systematic review showed that excessive weight gain in pregnancy was associated with macrosomia and postpartum weight retention, while inadequate weight gain was associated with preterm delivery and infants with low birth weight. ${ }^{9}$ Like obesity, pregnancy-related weight gain has not received much attention from researchers in this part of the world.

Studies on the scope of obesity in pregnancy in Nigeria are scarce, and the prevalence of obesity in pregnancy ranges from $5 \%$ to $10.7 \%$ of deliveries. ${ }^{6,7,10,11}$ Studies on the relative impact of obesity in pregnancy are even fewer, and we found no study that addressed weight gain in obese pregnant women in Nigeria. The aims of this study were to compare the patterns of maternal weight gain and obstetric outcomes between women with early pregnancy obesity and those with normal early pregnancy BMI in an urban obstetric population in South-East Nigeria.

\section{Materials and methods}

This study was conducted in three major urban maternity centers in the Enugu and Ebonyi states of Nigeria. Both states have a combined population of about 5 million people. ${ }^{12}$ The study centers were the University of Nigeria Teaching Hospital Ituku-Ozalla, Enugu State, Enugu State University Teaching Hospital, Park Lane, Enugu, and Federal Teaching Hospital (then Federal Medical Centre), Abakaliki, Ebonyi State. The three hospitals are tertiary medical centers with a combined annual delivery rate of over 6,000 during the study period.

The study population included all booked parturient women who delivered at the three major maternity centers between January 1, 2010 and December 31, 2011. The obstetric population in these hospitals is made up mainly of educated urban dwellers seeking care from specialists and coming to these hospitals by self-referral and also women referred from peripheral hospitals because of complicated pregnancies.

This was a retrospective cohort study involving women who delivered singleton babies. Cases were defined as parturient women who booked in the first trimester of pregnancy with a BMI in the obese range. Controls were defined as parturient women who booked in the first trimester with
BMI in the normal range and matched with cases in age and parity.

Written consent was obtained from all participating women. Recruitment of parturient women was done within 24 hours of delivery. The booking trimester of every parturient woman booked was noted. Consenting women who booked in the first trimester were selected and their booking weight and height were obtained, from which the booking BMIs were calculated according to the formula: weight $(\mathrm{kg}) /$ height $\left(\mathrm{m}^{2}\right)$. BMI classification was based on the World Health Organization classification (underweight $\leq 18.5 \mathrm{~kg} / \mathrm{m}^{2}$, normal $18.5-24.99 \mathrm{~kg} / \mathrm{m}^{2}$, preobese $25-29.99 \mathrm{~kg} / \mathrm{m}^{2}$, obese $\left.\geq 30 \mathrm{~kg} / \mathrm{m}^{2}\right) .{ }^{13}$ The last prenatal weight recorded within 2 weeks of delivery or the weight recorded on arrival in labor was also obtained.

For every consecutive consenting woman with a first trimester booking BMI in the obese range (case), the next parturient woman with a normal first trimester BMI matched with the corresponding obese case in age (within two years) and parity (nulliparous versus multiparous) was selected as control. The data for each parturient were captured using a pro forma. Data abstracted from case records of the women included age, parity, weight, height, history of prenatal complications such as gestational diabetes, malaria, hypertension/ pre-eclampsia, premature rupture of membranes, antepartum hemorrhage, gestational age at delivery, Apgar score at delivery, delivery mode, immediate postpartum blood loss, fetal birth weight, and placental weight. Excessive weight gain and inadequate weight gain were calculated based on the revised recommendations of the American Institute of Medicine (IOM) in $2009^{14}$ (see Supplementary Table 1).

The study data were analyzed with Statistical Package for Social Sciences software version 17.0 for Windows (IBM Corporation, Armonk, NY, USA) using descriptive and inferential statistics. Proportions and means of variables were calculated and cases were compared with controls based on these statistics. Main outcome measures were the proportions of cases and controls with abnormal weight gain as well as the proportions with different fetomaternal outcomes. Chisquare tests of significant difference were done for categorical variables and means of numerical variables were compared using the Student's $t$-test. The relationship between BMI and weight gain was determined using the Pearson's correlation coefficient. Unadjusted odds ratios (OR) for estimates were obtained, as well as $95 \%$ confidence intervals (CI). $P$-values $\leq 0.05$ were considered to be statistically significant. Ethical clearance for the study was obtained from the research ethics committee at each participating hospital. 


\section{Results}

There were a total of 6,651 parturient women who delivered in the three hospitals during the study period, of whom $1,806(27 \%)$ registered in their first trimester. Three hundred and forty of the $1806(17.9 \%)$ women were obese. Of the 340 obese women, 324 (95.3\%) consented to participate in the study and $16(4.7 \%)$ refused. Therefore, 648 women were studied, and comprised 324 women with early pregnancy obesity (cases) and 324 with normal early pregnancy BMI (controls).

\section{Sociodemographic characteristics}

The mean age was $26.7 \pm 5.1$ years in the obese women and $26.6 \pm 4.9$ years in the healthy-weight women. Mean parity was $1.6 \pm 1.4$ for obese women and $1.4 \pm 1.7$ for healthy-weight women. Obese women differed significantly from healthy-weight women in mean booking body mass index $(t=-29.07, P<0.000)$ and mean booking weight ( $t=21.30, P<0.000$ ), but not in mean age, parity, or height. Table 1 shows the sociodemographic characteristics of

Table I Comparison of demographic characteristics ${ }^{a}$

\begin{tabular}{|c|c|c|c|}
\hline Sociodemographic variable & $\begin{array}{l}\text { Obese } \\
n=324\end{array}$ & $\begin{array}{l}\text { Normal } \\
n=324\end{array}$ & $P$-value \\
\hline Age group (matched criterion) & & & 0.79 \\
\hline $10-20$ years & 26 & 30 & \\
\hline $21-30$ years & 228 & 225 & \\
\hline $31-40$ years & 64 & 60 & \\
\hline $4 I-50$ years & 6 & 9 & \\
\hline Occupation & & & $0.00 *$ \\
\hline Unemployed & 90 & 69 & \\
\hline Crafts & 18 & 89 & \\
\hline Civil servant/teacher & 66 & 48 & \\
\hline Student & 57 & 34 & \\
\hline Farmer & 3 & 6 & \\
\hline Trader & 81 & 72 & \\
\hline Professional & 9 & 6 & \\
\hline Educational status & & & $0.00 *$ \\
\hline University degree & 75 & 39 & \\
\hline Undergraduate student & 6 & 21 & \\
\hline Diploma/higher diploma & 54 & 123 & \\
\hline Senior secondary certificate & 24 & 30 & \\
\hline Junior secondary certificate & 123 & 87 & \\
\hline Primary school certificate & 36 & 15 & \\
\hline Marital status & & & 0.70 \\
\hline Married & 320 & 321 & \\
\hline Single & 4 & 3 & \\
\hline Residence & & & $0.00 *$ \\
\hline Urban dweller & 219 & 108 & \\
\hline Rural dweller & 105 & 216 & \\
\hline Parity group (matched criterion) & & & 0.85 \\
\hline Parous & 246 & 244 & \\
\hline Nulliparous & 78 & 80 & \\
\hline
\end{tabular}

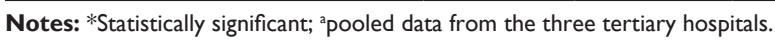

study subjects. Similarly, obese women differed significantly from healthy-weight women based on educational status, occupation, and residence, but not in marital status.

\section{Weight gain in pregnancy}

Comparison of weight gain in pregnancy between obese women and healthy-weight women showed that the mean weight gain in obese women was 8.3 (range $6.5-9.5$ ) kg while the mean weight gain in healthy-weight women was 11.1 (range 6.5-16.0) $\mathrm{kg}$. The difference in mean weight gains between obese women and healthy-weight women was not statistically significant $(t=1.23, P=0.25)$. There was a significant negative correlation between booking BMI and weight gain in pregnancy among obese women (Pearson's correlation coefficient $-0.999, P=0.02$ ). However, there was no significant correlation between booking BMI and weight gain among healthy-weight women (Pearson's correlation coefficient $0.12, P=0.80$ ). When weight gain was categorized as excessive based on the 2009 IOM recommendations, 38 obese women (11.7\%) and 89 healthyweight women $(27.5 \%)$ had excessive weight gain. The difference between proportions of obese and healthy-weight women who had excessive weight gain was statistically significant (OR 0.35, 95\% CI 0.23-0.54, $P<0.000$ ). For inadequate weight gain, also based on the IOM recommendations, 12 obese women (3.7\%) and 109 healthy-weight women $(33.6 \%)$ had inadequate weight gain, and the difference in proportions of women with inadequate weight gain was statistically significant (OR $0.08,95 \%$ CI $0.04-0.15$, $P<0.000)$.

\section{Obstetric outcomes}

A significantly higher proportion of obese women than healthy-weight women had adverse fetomaternal outcomes. These are summarized in Table 2. The proportions of parturients who had preterm and post term deliveries, early neonatal death, stillbirths, neonatal deaths, and shoulder dystocia did not differ significantly between obese and healthy-weight women.

Of obese women with excessive weight gain in pregnancy, 89.5\% (34/38) had at least one adverse fetomaternal outcome compared with $44.9 \%$ (40/89) of healthy-weight women. The difference in proportions of women with excessive weight gain who had adverse fetomaternal outcomes was significant $(P<0.001)$. Similarly, of obese women with inadequate weight gain, none $(0 / 12)$ had any adverse fetomaternal outcome compared with $54.1 \%$ (59/109) of healthyweight women. The difference in proportions of women with 
Table 2 Comparison of obstetric outcomes between obese and healthy-weight women

\begin{tabular}{lllll}
\hline Complication & $\begin{array}{l}\text { Proportion } \\
\text { in obese } \\
\text { women (\%) }\end{array}$ & $\begin{array}{l}\text { Proportion } \\
\text { in healthy- } \\
\text { weight } \\
\text { women (\%) }\end{array}$ & $\begin{array}{l}\text { Odds } \\
\text { ratio }\end{array}$ & $\begin{array}{l}95 \% \\
\text { confidence } \\
\text { interval }\end{array}$ \\
\hline $\begin{array}{l}\text { Premature } \\
\text { rupture of } \\
\text { membranes }\end{array}$ & 13 & 3.6 & 2.36 & $1.12-5.04$ \\
$\begin{array}{l}\text { Pre-eclampsia/ } \\
\text { eclampsia }\end{array}$ & 7.6 & 2.7 & 2.31 & $1.72-4.48$ \\
$\begin{array}{l}\text { Antepartum } \\
\text { hemorrhage }\end{array}$ & 5.4 & 1.2 & 2.78 & $1.02-7.93$ \\
$\begin{array}{l}\text { Gestational } \\
\text { diabetes }\end{array}$ & 1.8 & 0.03 & 4.28 & $1.62-11.74$ \\
$\begin{array}{l}\text { Cesarean } \\
\text { delivery }\end{array}$ & 37 & 18.1 & 4.3 & $1.2-5.44$ \\
$\begin{array}{l}\text { Postpartum } \\
\text { hemorrhage }\end{array}$ & 4.8 & 2.3 & 2.2 & $1.18-5.2$ \\
$\begin{array}{l}\text { Fetal } \\
\text { macrosomia }\end{array}$ & 42.1 & 18.5 & 4.08 & $1.06-8.4 \mathrm{I}$ \\
$\begin{array}{l}\text { Severe birth } \\
\text { asphyxia }\end{array}$ & 5.45 & 1.2 & 2.8 & $1.1-6.63$ \\
$\begin{array}{l}\text { Newborn } \\
\text { intensive care } \\
\text { admission }\end{array}$ & 8.7 & 4.0 & 1.18 & $1.0-3.29$ \\
\hline & & & & \\
\hline
\end{tabular}

inadequate weight gain who had an adverse fetomaternal outcome was also statistically significant $(P=0.001)$

\section{Discussion}

This is the first study in this area that has addressed the influence of early pregnancy obesity on maternal weight gain and on the occurrence of fetomaternal complications. Early pregnancy obesity was chosen as a proxy for prepregnancy obesity in view of a recent study in our region showing that most women did not know their prepregnancy weight and that early pregnancy BMI did not differ significantly from prepregnancy BMI. ${ }^{6}$ A retrospective cohort study of booked parturient women was chosen in order to maximize access to booked patients during their delivery; a prospective study could have been hampered by loss of study participants to follow-up occasioned by the tendency of pregnant women to register in multiple places and deliver in the most convenient place, as is common in our setting.

This study shows that, based on the latest recommendations of the IOM, ${ }^{14}$ among women with abnormal excessive weight gain in pregnancy, a higher proportion of obese women had at least one adverse outcome compared with healthy-weight women. A substantial proportion of healthy-weight women with excessive weight gain also had adverse outcomes. Conversely, inadequate weight gain was not associated with adverse outcomes in any obese woman. The results of this study suggest that obese women face the risk of adverse outcomes more when they gain excessive weight than when they have inadequate weight gain. This agrees with previous studies showing that complications such as pre-eclampsia, maternal hyperglycemia, infant macrosomia, late fetal death, birth defects, and an increased risk of cesarean section have been associated with excessive maternal weight gain. ${ }^{15-17}$ A recent systematic review shows that there is strong evidence linking weight gain above the IOM recommendation and high birth weight, macrosomia, and large-for-gestational-age babies, whereas there is only moderate evidence linking weight gain above the IOM recommendation, cesarean delivery, and maternal postpartum weight retention. ${ }^{15}$

For inadequate weight gain in pregnancy, the study shows that healthy-weight women tended to have more adverse outcomes than their obese counterparts. Moderate to strong evidence is available linking weight gain below the IOM recommendation and preterm birth, low birth weight, smallfor-gestational age, and failure to initiate breastfeeding. ${ }^{15}$ However, the mechanisms through which excessive weight gain might predispose to these complications independently have not been elucidated.

Obesity has also been known to be an independent risk factor for macrosomia, cesarean delivery, gestational diabetes, and pre-eclampsia through mechanisms related to labor dystocia and impaired maternal glucose metabolism. ${ }^{18}$ However, given that much fewer cases of excessive weight gain occurred among obese women in this study, it would appear that the finding of significantly more cases of preeclampsia, gestational diabetes, macrosomia, and abdominal delivery among the obese was due largely to the effects of obesity itself, not excessive weight gain. In other words, since more cases of excessive weight gain occurred among women with normal prepregnancy weight, the influence of prepregnancy obesity as an independent risk factor for these complications most likely outweighed any effects from excessive weight gain. These findings support the recommendation that "[...] focus should be on the nutritional health of women in the preconceptional period and on what weight loss interventions can be safely introduced in the obese woman seeking to become pregnant". ${ }^{3}$ This is one more reason why preconception care and planning should be promoted, even in developing countries like ours.

With respect to other maternal-fetal outcomes, the finding that significantly more women with early pregnancy obesity had fetomaternal complications, including prema- 
ture rupture of membranes, antepartum hemorrhage, severe birth asphyxia, abnormal Apgar scores, and neonatal special care baby unit admissions, confirms previously documented associations between obesity and these complications. In particular, the findings in this study agree with the study by Ezeanochie et al in South-South Nigeria. ${ }^{7}$ The mechanism via which obesity predisposes to severe birth asphyxia, abnormal Apgar scores, and newborn intensive care admissions could be related to its tendency to increase fetal macrosomia and labor dystocia, as well an increased occurrence of preeclampsia (and perhaps intrauterine growth restriction often associated with it) and gestational diabetes. Antepartum hemorrhage may result from a large placenta associated with both large babies and gestational diabetes or from placental abruption from severe gestational hypertension.

In relation to our environment, the results of this study once again show that obesity in pregnancy can contribute to the already poor maternal morbidity and mortality statistics in our country and that it could place a heavy burden on the health resources needed for maternal-fetal care unless measures are taken to curtail its growing prevalence. Therefore, there is a need for more public health campaigns on the adverse effects of obesity in pregnancy directed specifically to urban populations, where sedentary lifestyles and a shift to a Caucasian diet are predominant.

The strengths of this study include its multicenter design, which may improve the external validity of the findings, and the use of matched controls to minimize confounders. Its major drawbacks include its small sample size in relation to the general obstetric population, the retrospective nature of some of the data, and the fact that inaccuracies in weight and height measurements could not be ruled out as a result of this. Also, empiric observation shows that women who book in the first trimester in our area are often those who have heightened anxiety about their pregnancy, such as those with prior infertility or those with complications in a previous or current pregnancy. This scenario could introduce some bias due to the possibility of unintended selection of women with complicated pregnancies by limiting the sample to those who booked in the first trimester.

However, we conclude that early pregnancy obesity is associated with substantial adverse fetomaternal outcomes in comparison with healthy-weight women. Although abnormal weight gain occurred less frequently in obese women compared with healthy-weight women, the proportion of obese women with excessive weight gain who had adverse outcomes was higher than in healthy-weight women. The greater occurrence of fetomaternal complications associated with obesity in our environment is more likely to be due to the effect of obesity itself rather than abnormal weight gain in pregnancy. Women in this low-resource setting should be encouraged to attain a healthy prepregnancy weight in order to reduce maternal morbidity and mortality. We recommend the introduction of public enlightenment on the need for women to adopt nutritional measures to maintain appropriate prepregnancy weights and also ensure normal weight gain during pregnancy in our environment.

\section{Acknowledgments}

We thank Drs Augustine Asogwa, Emeka Onyia, and Ugochukwu Ezenyirioha, as well as the nursing staff of the labor wards at the University of Nigeria Teaching Hospital, Enugu State University Teaching Hospital (ESUTH), and Federal Medical Centre Abakaliki for their assistance with collection of data for this study.

\section{Disclosure}

The authors report no conflicts of interest in this work.

\section{References}

1. World Health Organization. Diet nutrition and the prevention of diseases: report of a joint WHO/FAO expert consultation. Technical report series 916. Geneva, Switzerland: World Health Organization; 2002. Available from: http://www.who.int/dietphysicalactivity/ publications/trs916/kit/en/. Accessed July 20, 2013.

2. World Health Organization. Obesity and overweight. Fact sheet 311. Geneva, Switzerland: World Health Organization; 2013. Available from: http://www.who.int/mediacentre/factsheets/fs311/en/. Accessed June 30, 2013.

3. Vinayagam D, Chandraharan E. The adverse impact of obesity on intrapartum and perinatal outcomes. ISRN Obstet Gynecol. 2012; 2012:939762.

4. Heslehurst N, Simpson H, Ells LJ, et al. The impact of maternal BMI status on pregnancy outcomes with immediate short-term obstetric resource implications: a meta-analysis. Obes Rev. 2008;9:635-683.

5. Verdiales M, Pacheco C, Cohen WR. The effect of maternal obesity on the course of labour. J Perinat Med. 2009;37:651-655.

6. Chigbu CO, Ajah LO. Obesity in pregnancy in South East Nigeria. Ann Med Health Sci Res. 2011;1:135-140.

7. Ezeanochie MC, Ande AB, Olagbuji BN. Maternal obesity in early pregnancy and subsequent pregnancy outcome in a Nigerian population. Afr J Reprod Health. 2011;15:55-59.

8. Zhang S, Rattanatray L, Morrison JL, Nicholas LM, Lie S, McMillen IC. Maternal obesity and early origins of childhood obesity: weighing up the benefits and costs of maternal weight loss in the periconceptional period for the offspring. Exp Diabetes Res. 2011;2011:585749.

9. Viswanathan M, Siega-Riz AM, Moos M, et al. Outcomes of maternal weight gain. Evidence Report/Technology Assessment 168. Rockville, MD: Agency for Healthcare Research and Quality; 2008. Available from: http://www.ahrq.gov/research/findings/evidence-based-reports/ er168-abstract.html. Accessed July 20, 2013.

10. Jeremiah I, Nyeche S, Akani C, Akani N. Pregnancy outcome among obese parturients at the University of Port Harcourt Teaching Hospital, Nigeria. J Med Med Sci. 2011;2:1152-1156.

11. Obi SN, Obute EA. Pregnancy outcome in the obese Nigerian. Trop $J$ Obstet Gynaecol. 2004;21:32-35. 
12. National Population Commission (Nigeria) and ICF Macro. Nigeria Demographic and Health Survey 2008. Abuja, Nigeria: National Population Commission and ICF Macro; 2009. Available from: http://www.measuredhs.com/pubs/pdf/FR222/FR222.pdf. Accessed July 20, 2013.

13. World Health Organization. Global database on body mass index: BMI classification. Available from: http://apps.who.int/bmi/index.jsp. Accessed June 13, 2013.

14. Institute of Medicine. Weight Gain During Pregnancy: Reexamining the Guidelines. Washington, DC: The National Academies Press; 2009.

15. Oken E, Kleinman KP, Belfort MB, Hammitt JK, Gillman MW. Associations of gestational weight gain with short- and longer-term maternal and child health outcomes. Am J Epidemiol. 2009;170: 173-180.
16. Rasmussen K, Yaktine A. Weight Gain during Pregnancy: Re-examining the Guidelines. Washington, DC: The National Academies Press; 2009.

17. Siega-Riz AM, Viswanathan M, Moos MK, et al. A systematic review of outcomes of maternal weight gain according to the Institute of Medicine recommendations: birth weight, fetal growth, and postpartum weight retention. Am J Obstet Gynecol. 2009;201:339. e1-339. e14.

18. Parsons TJ, Power C, Manor O. Fetal and early life growth and body mass index from birth to early adulthood in 1958 British cohort: longitudinal study. BMJ. 2001;323:1331-1335. 


\section{Supplementary table}

Table SI New recommendations from the Institute of Medicine for total weight gain during pregnancy according to prepregnancy BMI*

Prepregnancy BMI

Recommended total weight gain (kg)

Underweight $\left(<18.5 \mathrm{~kg} / \mathrm{m}^{2}\right)$

12.5-18

Normal weight $\left(18.5-24.9 \mathrm{~kg} / \mathrm{m}^{2}\right)$

II.5-16

Overweight $\left(25-29.9 \mathrm{~kg} / \mathrm{m}^{2}\right)$

$7-11.5$

Obese $\left(\geq 30.0 \mathrm{~kg} / \mathrm{m}^{2}\right)$

5-9

Note: *Based on 2009 recommendations.

Abbreviation: BMI, body mass index.

\section{Publish your work in this journal}

The International Journal of Women's Health is an international, peerreviewed open-access journal publishing original research, reports, editorials, reviews and commentaries on all aspects of women's healthcare including gynecology, obstetrics, and breast cancer. The manuscript management system is completely online and includes a very quick and fair peer-review system, which is all easy to use. Visit http://www.dovepress.com/testimonials.php to read real quotes from published authors.

\footnotetext{
Submit your manuscript here: http://www.dovepress.com/international-journal-of-womens-health-journal
} 